\title{
IMAGINATIVE TRANSPORTATION
}

\section{Samuel Kampa}

[Published in Australasian Journal of Philosophy 96.4: 683-96 [2018]. Version of Record available online at http://www.tandfonline.com/10.1080/00048402.2017.1393832. Please cite VoR.]

Actors, undercover investigators, and readers of fiction sometimes report "losing themselves" in the characters they imitate or read about. They speak of "taking on" or "assuming" the beliefs, thoughts, and feelings of someone else. I offer an account of this strange but familiar phenomenon-what I call imaginative transportation.

Keywords: imagination, transportation, immersion, pretense

\author{
There is no Frigate like a Book \\ To take us Lands away, \\ Nor any Coursers like a Page \\ Ofprancing Poetry - \\ This Traverse may the poorest take \\ Without oppress of Toll- \\ How frugal is the Chariot \\ That bears a Human soul - Emily Dickinson (1873)
}

\section{Introduction}

Stories wield a strange sort of power. That this power is strange is evidenced by the fact that we rely almost entirely on metaphors to describe it. We say that stories "transport us," that they "draw us away" from the real world and into worlds of fancy. Even more mysteriously, we speak of "taking on the identities" of characters we encounter in fiction. When we become caught up in a story, it is as if our beliefs and desires are replaced, for a time, by those of the character or characters with whom we in some way identify. In losing ourselves in stories, we assume a 
strange sort of attitude vis-à-vis the propositions of fiction; it is as if we really believe what we are reading. ${ }^{1}$ Case in point:

READER. Sandra has been reading Mary Shelley's Frankenstein for hours on end. She is working through a monologue from Frankenstein's monster in which the monster (rather eloquently) details his personal and intellectual development, describes the abuses and humiliations he has endured, and rails against the creator who abandoned him. Sandra is utterly captivated by the story-so much so that she has lost track of time and forgotten, as it were, who she is and where she is. She thinks the monster's thoughts and feels the monster's pain; it is as if the monster's testimony is her own. She feels, for a time, that she and the monster are one.

I take the phenomenon described in READER to be familiar enough, if rather strange on reflection. ${ }^{2}$ We see this phenomenon at work not only in literary experiences, but also in the experiences of those who publicly take on roles, such as actors, spies, and con artists:

AGENT. Meredith is an undercover FBI agent. For years, she has been in the confidence of Scary Carrie, the mastermind behind the largest drug-smuggling operation in North America. Meredith has so gained Carrie's trust that she has officially become Carrie's second-in-command. Out of necessity, Meredith spends far more time managing the affairs of Carrie's empire than communicating with her contacts in the Bureau. For Meredith, her assumed reality has become increasingly unsettling. She is utterly caught up in the deception, to the point that she almost forgets, at times, who she really is. She fears that she is losing herself.

\footnotetext{
1 Price [1969: 307-8], Liao and Doggett [2014: 259-60], and Liao [unpublishable: 1-3] offer similar characterizations of the phenomenon.

${ }^{2}$ See Green and Donahue [2009] and Kaufman and Libby [2012] for cases, along with empirical analysis.
} 
GIOVANNI. John is a model family man: gentle, selfless, guileless, and fiercely loyal. But on weekday evenings, he is a very different sort of person. No, he does not have a secret life; on the contrary, his indiscretions are quite public. John is an opera singer currently playing Don Giovanni. In an art form notorious for stodgy acting, John prides himself on being a method actor. Each time he takes the stage, John becomes his character-thinking, moving, and leering just like the title libertine. Off stage, he is a good and noble man. On stage, he is a womanizing bastard. ${ }^{3}$

Sandra, Meredith, and John all seem to be in roughly the same sort of state. But what, exactly, is this state? That is the central question of this paper.

I begin by considering and rejecting some candidate cognitive attitudes that one might take the above cases to exemplify. I suggest that each case is an instance of imaginative transportation. ${ }^{4}$ After drawing out some of the central features of imaginative transportation, I develop a cognitive model to further elucidate the phenomenon.

\section{The Usual Suspects, and What They Miss}

An epistemologically-informed reader might suspect that READER, AGENT, and GIOVANNI are cases of full belief, imaginative pretense, alief, in-between belief, or half-belief. They are not. In what follows, I discuss each attitude and show that it is not exemplified by the foregoing cases. Doing so will help bring out central features of imaginative transportation and pave the way for a positive account.

\footnotetext{
3 AGENT and GIOVANNI are inspired by Langland-Hassan's [2014: 397-8] cases of "deceptive pretense" and "theatrical pretense," respectively.

${ }^{4}$ The concept is not new, though it receives different treatments in psychology and philosophy, and it isn't particularly well-developed in the philosophical literature. Social psychologists provide accounts of transportation [Green and Donahue 2009] and experience-taking [Kaufman and Libby 2012], though they tend to be more interested in explaining empirical data than developing cognitive models. Susanna Schellenberg [2013] develops a cognitive model of imaginative immersion, with Liao and Doggett [2014], Liao [unpublishable], and Chasid [2017] proposing rivaling accounts. Conversation with Liao has convinced me that imaginative transportation is distinct from imaginative immersion and perhaps closest in spirit to Kaufman and Libby's notion of experience-taking — or perhaps Walton's [1990: 28-35] notion of imagination de se. I distinguish transportation from immersion in footnote 25.
} 
READER, AGENT, and GIOVANNI are not cases of full belief. It is an epistemological platitude that to believe that $p$ is to believe that $p$ is true. Does Sandra believe that I am the creation of Dr. Frankenstein is true; Meredith that I am a career drug trafficker is true; or John that I am a libertine is true? Certainly not. They know just as well as anyone else that they are neither monsters nor career traffickers nor libertines. This isn't to say that the states in question are not belief-like. Indeed, Sandra, Meredith, and John exhibit behaviors, thoughts, and feelings that, ceteris paribus, are characteristic of full belief. John, for example, is disposed to exhibit many of the behaviors, thoughts, and feelings that we would expect to find in one who really took himself to be Don Giovanni.

But of course, John does not in fact believe that he is Don Giovanni. How do we know this? First, because nothing in GIOVANNI suggests that John is delusional; but John would be delusional were he to really take himself to be Don Giovanni. Method actors may be guilty of excessive intensity, ${ }^{5}$ but surely they aren't guilty of delusional thinking-not ordinarily, at least. ${ }^{6}$ Second, John's dispositions lack the stability characteristic of full belief. If a fire breaks out in the opera house, the spell of the performance is broken. John will run for his life, not as Don Giovanni, but as a twenty-first century man desperate to return to his family. But it isn't just that John's belief-like dispositions are unstable; in another sense, they're quite stable. While a fire might break the spell of the performance, a flashing camera will not. ${ }^{7}$ That John can "stay in the moment" through a flashing camera suggests another feature of John's belief-like state that distinguishes it from full belief. If John really believed that he was Don Giovanni, even for a moment, we would expect him to react in terror at the flash of a camera. ("What is this sorcery?" he might ask.) But John doesn't react in terror, because John doesn't really believe that he is Don

\footnotetext{
${ }^{5}$ Hollywood legend has it that method actor Dustin Hoffman once deprived himself of sleep for three days in preparation for a scene. Upon seeing the exhausted man shuffle onto the set of Marathon Man, the preeminent Laurence Olivier asked: "My dear boy, why don't you try acting?"

${ }^{6}$ Liao and Doggett [2014: 270] put the point well: "When people respond to a method actor who will not give up a character, the response that makes sense is frustration — give up the game! — rather than pityhe has lost his grip on reality."

${ }^{7}$ See Liao and Doggett [2014: 269] for an explanation of this phenomenon.
} 
Giovanni-and this despite his behaving, thinking, and feeling like Don Giovanni. ${ }^{8}$ Clearly, belief is unnecessary for character assumption.

Perhaps the state in question is less like full belief and more like make-believe, or "imaginative pretense" as it is sometimes called. Recent work on imaginative pretense is largely occupied with pinning down just what imaginative pretense is-a debate I needn't settle here. Instead, I will stipulate as theoretically neutral a definition as I can muster. To engage in imaginative pretense with respect to $p$ is to imagine that $p$ is true and pretend (through one's behavior or otherwise) that $p$ is true. ${ }^{9}$ John, then, engages in imaginative pretense with respect to the proposition I am Don Giovanni in the event that he imagines I am Don Giovanni is true and pretends to be Don Giovanni (by, say, bragging about his conquests).

Character assumption more closely resembles pretense than belief, but character assumption is not the same as pretense. To see why, consider the following pretense-style versions of READER, AGENT and GIOVANNI:

PRETENSE-READER. Having been assigned to read Frankenstein for her Victorian Literature course, Pretense-Sandra is absently reading the monster's monologue as she listens to a podcast. Though she conjures images of the scene in her head and occasionally asks herself what she would do in the monster's shoes, she is far from immersed in the story. The monster's plight commands only her partial attention.

PRETENSE-AGENT. Pretense-Meredith has been working undercover for three months. She is still getting a feel for her assignment and has not quite taken on the role to which she has been assigned. Whenever she interacts with Scary Carrie, she thinks to herself, how would one of Carrie's minions behave? While she does her level best to play the part, she is unceasingly aware of her identity as an FBI agent.

\footnotetext{
${ }^{8}$ Schellenberg [2013: 508-9] raises similar points about belief and performance.

${ }^{9}$ See footnote 13. See also Liao and Gendler [2011] for a survey of literature on imaginative pretense.
} 
PRETENSE-GIOVANNI. Pretense-John is a stereotypical opera singer: a stiff actor with a million-dollar voice. When he performs, he thinks only of vocal mechanics: the depth of his breaths, the purity of his vowels, the quality of his diction, and the like. When it comes to the acting, John is operating on auto-pilot.

READER, AGENT, and GIOVANNI are not equivalent to their pretense-style counterparts. What separates these two groups of cases? We can distinguish along four dimensions: commitment required, demandingness, skill required, and effectiveness.

Sandra, Meredith, and John are more committed to their characters than their pretensestyle counterparts. They feel a sense of closeness with their assumed characters that mere pretense cannot afford. Consider a report from Deborah Margolin, actor and professor of Theatre Studies at Yale University, on committing to the role of an unhappy woman:

It was depressing...My character would cry, and I would cry. She was miserable, and I was miserable. She was a frustrated, ignorant person trapped in a narrow life, and I felt like that. Once, while I was onstage, my purse was robbed in the dressing room, and I felt like everybody backed away from me, thinking that I would infect them with tragedy. These were lovely people-I loved them dearly_but my character was unattractive and somehow, so was I [Ohikuare 2014].

Performance lore is replete with similar tales of dedicated actors losing themselves in the characters they inhabit. ${ }^{10}$ Like Deborah, Sandra, Meredith, and John embody their respective characters in ways that their pretense counterparts do not. There is a sense in which the former, but not the latter, are their characters.

Margolin's report also brings out the demanding nature of assuming a role. Character assumption is cognitively, emotionally, and physically taxing, eclipsing the effort expended in mere pretense. Consider a working actor's reflections on the difficulties of live performance:

${ }^{10}$ See Brody [2014] and Liao and Doggett [2014: 259] for more anecdotes on method acting, along with analysis. 
Great acting should [look] effortless, natural and easy. And so, it is often misjudged as actually effortless, natural and easy ...A few years back I was lucky enough to play Othello. People would come up to me after curtain-down and say "how did you manage to learn all those lines"? Learning lines was the easiest part of the process. Going from a place of complete devotion to one's wife to absolute murderous intent, within a 20-minute scene, was quite a bit harder...How does it feel to rehearse a scene in which I am being interrogated by the police as a suspected pederast? Well, on a good day, when it all comes together and everyone is firing on all cylinders, it feels like I was interrogated by the police as a suspected pederast...That is the job [Andreou 2014].

The first lesson to draw from Andreou's reflections is that it is one thing to pretend to be Othello: to wear the costume, hit the right marks, recite the lines, and so on. It is quite another to fully commit to the role.

The second lesson is that assuming a character requires considerable skill. Acting is a craft, after all. As such, it requires years of rigorous training and more than a trace of natural acumen. Meryl Streep and Dustin Hoffman are paid handsomely in part because they do what we cannot. We might say the same of Meredith and John; few can truly immerse themselves in the role of a drug trafficker or a seventeenth-century libertine. It takes talent, education, and practice.

It might be objected that pretense requires skill too. Fair enough. But whatever skill is exercised in pretense is quite different from that exercised in character assumption. Paradigmatically, skills are the sorts of things one can succeed or fail in exercising. One can attempt to assume a character and fail; even good actors have "off days." On the other hand, one cannot attempt to pretend and fail. One can fail to pretend well-as anyone who has endured a high school musical can attest—but in general, one cannot fail altogether to pretend. ${ }^{11}$

Finally, assuming a character is often thought to be more effective than mere pretense in the following sense: those who assume their characters seem more closely to resemble their

${ }^{11}$ There are exceptions to the rule. I can fail to pretend to be a hectagon. I can also fail to pretend to be a liger if I don't know what a liger is. But generally, pretense is far more automatic than transportation. 
characters than those who merely pretend. ${ }^{12}$ Method actors are more convincing to their audience than mere pretenders_or so the story goes. I will say more about effectiveness in section 3; for now, suffice it to say that assuming a character is often thought better for practical purposes than mere pretense.

The upshot of all of this is that Sandra, Meredith, and John are not engaging in mere pretense. Whatever state they are in requires more skill and commitment and is more demanding and effective than garden-variety pretense. At the very least, pretense is insufficient for character assumption. $^{13}$

Perhaps character assumption is closer to alief_a notion due to Tamar Gendler [2008]. Alief is a complex cognitive state whose content is representational (where the representation is conceptual, propositional, or otherwise), affective (in the sense that the state is emotionally valenced), and behavioral (in the sense that it causally contributes to certain sorts of behaviors). Importantly, aliefs are often belief-discordant; one can alieve that which one explicitly disavows. For an example of belief-discordant alief, Gendler cites a series of experiments conducted by Paul Rozin in which test subjects refused to eat feces-shaped fudge, citing its disgusting appearance. When asked whether they believed the fudge really was feces, subjects readily denied it. What the subjects alieved-namely, an associative complex with content: Feces, Eew! Don't eat_conflicted with what the subjects explicitly avowed (and, plausibly, what the subjects in fact believed) [Gendler 2008: 635-6].

\footnotetext{
${ }^{12}$ I do not mean to suggest that method acting is in fact more effective than garden-variety acting. Indeed, Laurence Olivier's acting prowess is strong countervailing evidence. (See footnote 5.) I am merely drawing attention to the fact that practitioners tout method acting because they think it results in more realistic performances. The success of my account does not turn on the veracity of practitioners' claims. (Thanks to Jason D'Cruz for inviting me to clarify.)

${ }^{13}$ Nathan Ballantyne, Robert Duffy, and an anonymous reviewer raised the possibility that transportation might simply be demanding, skillful, and effective pretense, or perhaps pretense plus attention. While I'm not opposed to the idea, its plausibility ultimately hangs on whether pretense requires overt behavior. If the answer is yes-the most popular answer in the pretense literature, if my cursory survey is representative- then transportation is not a species of pretense, since readers can be transported without engaging in pretense behavior. But if the answer is no, then it's possible that transportation is a species of pretense. As the matter is outside the scope of this paper, I have elected not to take a side.
} 
Character assumption shares features with alief. It is representational in so far as one "takes on" the representational states of one's character, affective in so far as assuming a character generates emotional responses, and behavioral in so far as taking on a character leads one to act like one's character. And like alief, character assumption can be in tension with one's avowed beliefs. ${ }^{14}$ Moreover, actors can alieve all sorts of things while performing. (In the course of a drug transaction gone awry, Meredith might alieve: Weapon, Danger! Run away.)

But character assumption is not alief. The sense in which alief can conflict with belief is not the sense in which character assumption can conflict with belief. When one's aliefs conflict with one's rational beliefs, irrationality results. For example, it is uniquely rational for the subjects in Rozin's study to believe that the feces-shaped fudge is not, in fact, feces. In light of this, it is irrational for the subjects to turn away from the fudge with disgust. ${ }^{15}$ On the contrary, there is no such consistency requirement for character assumption. While it is uniquely rational for John not to believe that he is Don Giovanni, it is in no sense irrational for John to think, feel, and act like Don Giovanni. Alief thus differs from character assumption in that, while it is in some sense irrational to alieve in ways inconsistent with one's rational beliefs, it is in no way irrational, in the course of assuming a character, to think, feel, and act in ways inconsistent with one's rational beliefs.

Character assumption is also not acceptance, where to accept that $p$ is to "have or adopt a policy of deeming, positing, or postulating that $p$-i.e. of including that proposition or rule among one's premises for deciding what to do or think in a particular context" [Cohen 1992: 4]. Admittedly, there is a sense in which actors premise their decisions on acceptances. John, under the guise of Don Giovanni, might take it as a premise that he need not repent of his

\footnotetext{
14 Compare with Price [1969: 313].

${ }^{15}$ Though Gendler [2008: 656-63] characterizes aliefs as arational rather than irrational, she maintains that aliefs are at least sometimes causally responsible for irrational behaviors. The same cannot be said for imaginative transportation, however; there is nothing per se irrational about it. Compare with Price [1969: 313-4].
} 
womanizing, not because John actually believes this, but because his character believes it, and because John is committed, for practical reasons, to act like his character while on stage.

But character assumption is different. To see why, consider the fact that acceptance is closed under subjective deducibility. If one accepts $p$ and accepts $p \rightarrow q$, then one ipso facto accepts $q$ [Cohen 1992: 27-33]. But John's so-called acceptances are not subjectively closed. Say that John accepts I am Don Giovanni (p). It is at least open to John to accept if I am Don Giovanni, then I am not an actor $(p \rightarrow q)$. But surely, John both believes and accepts the proposition I am an actor $(\sim q)$; if he flubs a line on stage, he will get himself back on track, just as an actor (but not Giovanni) would. Since John's “acceptances" are not closed under subjective deducibility, we should deny that John's attitude vis-à-vis I am Don Giovanni is genuine acceptance. John does not accept I am Don Giovanni. Rather, John accepts I am playing the character of Don Giovanni, while John's character accepts I am Don Giovanni.

Other candidate attitudes can be ruled out swiftly. Assuming a character is not a matter of in-between believing, where to be in a state of in-between belief with respect to $p$ is for there to be no context-independent fact of the matter whether one believes $p$ [Schwitzgebel 2001]. On the contrary, there is a fact of the matter whether John believes he is Don Giovanni; the fact is he doesn't. Similarly, assuming a character is not a matter of half-believing, where to half-believe that $p$ is to fully believe $p$ in some contexts, but not others. ${ }^{16}$ John fully believes that he is Don Giovanni neither on- nor off-stage. Rather, he fully and persistently believes its negation.

READER, AGENT, and GIOVANNI are not cases of full belief, imaginative pretense, acceptance, in-between belief, or half-belief. I hereafter use the term imaginative transportation to refer to the attitude exemplified by Sandra, Meredith, and John. In the space that remains, I develop a more detailed account of the phenomenon.

\footnotetext{
${ }^{16}$ The notion of half-belief I have in mind is essentially Price's [1969: 306] notion of religious half-belief. A religious half-believer genuinely believes that God exists on Sundays and genuinely disbelieves that God exists Monday through Saturday [cf. Schwitzgebel 2001: 78]. My notion of imaginative transportation is closer to Price's notion of aesthetic half-belief [1969: 307-8].
} 


\section{An Account of Imaginative Transportation}

Before proceeding, allow me a brief word on terminology. The verbal form of "pretense" is "pretend," as in "John pretends that he is Don Giovanni." But "imaginative transportation," alas, has no such counterpart. (Of course, it is sometimes permissible to bend natural language in service of a philosophically noble end; but "John transports that he is Don Giovanni" is well beyond the pale.) Several terms have been suggested to me, but each, in my view, is misleading. ${ }^{17}$ For the time being, I have settled for a rather monstrous neologism, namely, palieve. Why I have resorted to this particular monstrosity, and not another, will become clear in due course.

I begin by defining the monster I've created:

PALIEF. To palieve that $p$ is to virtually assume a noetic structure that includes $p$.

Just as "S pretends that $p$ " is equivalent to "S engages in imaginative pretense with respect to $p$," so "S palieves that $p$ " is equivalent to "S engages in imaginative transportation with respect to $p$. ." And just as one can have a particular belief, so one can have a particular palief. As per section 2, palieving that $p i$ ) is not identical to belief, pretense, alief, acceptance, in-between belief, or halfbelief; ii) is rationally consistent with believing that not- $p$; iii) is cognitively taxing, $i v$ ) generally requires considerable effort, $v$ ) generally exercises special skills, vi) is thought to effectively serves certain practical ends, and vii) generally elicits affective responses. I have already dedicated a fair bit of space to (i)-(vii), so I'll leave them aside for now. Instead, I shall focus on identifying additional features of imaginative transportation and developing a cognitive model that captures these features.

To bring out additional features of palief (and to justify my use of the term), let us again compare it with alief. Like aliefs, paliefs are arational, affect-laden, and action-generating. ${ }^{18}$

17 "Seriously pretend" and "sincerely pretend" are among the terms that have been suggested to me. While far more natural than "palieve," these terms suggest that imaginative transportation is a species of imaginative pretense. For reasons outlined in footnote 13, I am neutral on the question of reduction.

${ }^{18}$ See Gendler [2008: 641-2]. 
Paliefs are arational in the sense that they are, by their very nature, not reasons-responsive. John's palief that he need not repent of his womanizing is unresponsive to countervailing evidence, not because John's palief is defective, but because paliefs just aren't the sorts of things that are evidentially responsive. Moreover, paliefs are not semantically evaluable; John's paliefs are neither true nor false. ${ }^{19}$ Paliefs also tend to be affect-laden; when Sandra palieves that her creator abandoned her, she feels rejected. And paliefs are action-generating; Meredith's paliefs lead her to behave in new and unsettling ways.

But unlike aliefs, paliefs are propositional (not associative), purposeful (not automatic), held only by persons (not shared with non-human animals), and developmentally and conceptually posterior (not antecedent) to other cognitive attitudes. ${ }^{20}$ While paliefs may be affectand action-generating, their objects are propositions, not complexes of representational, affective, and behavioral dispositions. ${ }^{21}$ Paliefs are purposeful in the sense that they are often maintained on purpose (not as a result of automatic processing) and in the sense that they serve practical purposes. Meredith and John choose to engage in imaginative transportation so as to achieve some practical end, be it deception or entertainment. Moreover, it seems plausible that, owing to its propositional character and cognitive demandingness, palieving is an exclusively human activity. It is also plausible that palieving is developmentally and conceptually posterior to at least some other cognitive attitudes. For example, one cannot palieve without being able to believe, and one cannot have a concept of palief without having a concept of belief, since palieving that $p$ requires thinking as if one really believes that $p$.

As per our definition, to palieve that $p$ is to virtually assume a noetic structure that includes p. My notion of noetic structure is due to Alvin Plantinga [1983: 48]: “A person's noetic

\footnotetext{
${ }^{19}$ Compare with Schellenberg [2013: 499].

${ }^{20}$ Compare with Gendler [2008: 641-2].

${ }^{21} \mathrm{My}$ reason for favoring a propositional account over an associative account is largely practical, and perhaps borne of an inordinate attachment to alliteration. For the purposes of the model, treating paliefs as propositional attitudes rather than associative attitudes makes life easier. It is also worth noting that Gendler [2008: 646] is somewhat ambivalent about treating aliefs as associative rather than propositional attitudes. In any event, this part of my account is revisable.
} 
structure is the set of propositions he believes, together with certain epistemic relations that hold among him and these propositions." Among the relations partly constitutive of a noetic structure are basicality, degree, and ingress relations. ${ }^{22} \mathrm{~A}$ full specification of Don Giovanni's noetic structure thus includes the set of propositions he believes along with relations of support between propositions (for example, Zerlina is highly attracted to me because I am eminently desirable), assignments of credences to propositions (for example, $\mathrm{B}_{\text {Giovanni }}$ (Zerlina is highly attracted to me) $=$ 1.0), and relations of ingress (for example, I am eminently desirable is deeper than three weeks ago, I ate an apple).

By way of sharpening what is yet a fuzzy notion, I shall sketch one of the more influential cognitive models of imaginative pretense on offer, courtesy of Nichols and Stich [2000], before exploiting its architecture and adapting it to imaginative transportation. Nichols and Stich's account begins with a common representationalist picture of propositional attitude storage and access. ${ }^{23}$ Imagine that your mind is, among other things, a storehouse of various boxes, where each box contains representation tokens, and where boxes are distinguished one from another by the functional and computational properties of the attitudes associated with each box. Thus, you believe that $p$ just in case $p$ is stored in your Belief Box; you desire that $p$ just in case $p$ is stored in your Desire Box; and so on. Nichols and Stich suggest that, in addition to the usual boxes, you also have a Possible World Box, where your Possible World Box contains tokens with contents like I am Dr. Frankenstein's creation and Zerlina is bighly attracted to me. They elaborate:

\footnotetext{
${ }^{22}$ For an agent $\mathrm{S}$ and propositions $p$ and $q, \mathrm{~S}$ believes $p$ on the basis of $q$ just in case $\mathrm{S}$ believes $p$ because she believes $q$ (where "because" is used in a causal or justificatory sense); $\mathrm{S}$ believes $p$ to degree $n$ just in case $\mathrm{S}$ is $(100 n) \%$ certain that $p$; and $p$ has greater depth of ingression than $q$ just in case $p$ is closer to the "center" of S's noetic structure than $q$-i.e., removing $p$ from S's noetic structure creates a greater "ripple effect" than removing $q$. See Plantinga [1983: 48-52].

${ }^{23}$ I suspect that one could come up with a dispositionalist-friendly version of the following account. But if there is no satisfactory dispositionalist account of imaginative transportation, so much the worse for dispositionalism.
} 
Like the Belief Box and the Desire Box, the Possible World Box contains representation tokens. However, the functional role of these tokens, their pattern of interaction with other components of the mind, is quite different from the functional role of either beliefs or desires. Their job is not to represent the world as it is or as we'd like it to be, but rather to represent what the world would be like given some set of assumptions that we may neither believe to be true nor want to be true. The [Possible World Box] is a work space in which our cognitive system builds and temporarily stores representations of one or another possible world [2000: 122].

This Possible World Box, Nichols and Stich explain, supplies the representational content of pretense episodes. Say that John intends to pretend I am Don Giovanni. Upon executing this intention, a representation token with content I am Don Giovanni is placed in John's Possible World Box. To fill out the details of the pretense, representation tokens from John's Belief Box are filtered for consistency with the Giovanni pretense, funneled into his Possible World Box, and employed to generate pretense-based inferences. Thus, during the pretense episode, John's Possible World Box is filled with additional representation tokens with contents like Zerlina is highly attracted to me or the commendatore deserved to die, depending on how the pretense unfolds. By thus accessing, using, and adding tokens to the Possible World Box, John is able to engage in dynamic pretense episodes. Importantly, his Belief and Desire Boxes retain their respective contents throughout the pretense, which is just to say that John's beliefs and desires don't change. That the contents of the Possible World Box are quarantined from those of the Belief Box also ensures that the former contents can conflict with the latter without precipitating doxastic revision or generating cognitive dissonance. It is thus easy to explain on the model how one can pretend that $p$ but believe that not- $p$.

Nichols and Stich offer a helpful way of conceptualizing what goes on in episodes of pretense. Indeed, it is a small step to extend the account to imaginative transportation. For in episodes of both transportation and pretense, one i) executes an intention to think and behave in ways that might conflict with one's beliefs and desires (thereby placing a representation token in one's Possible World Box); ii) uses beliefs to fill out the details of the pretense or palief (thereby filtering tokens from the Belief Box into the Possible World Box); and iii) retains one's beliefs 
and desires through the episode (thereby keeping the contents of one's Belief and Desire Boxes the same). But now, imaginative transportation looks quite like pretense. One might wonder whether imaginative transportation is just garden-variety pretense.

In section 2, I offered reasons for resisting this last suggestion, and I'm sticking to those reasons. But I am not recommending revisions to the current architectural model. Indeed, it would be better, all things considered, if we didn't clutter our storehouse with new boxes or mechanisms. ${ }^{24}$ Instead, I suggest that the difference between palief and pretense appears not at the level of boxes and mechanisms, but rather at the level of cognitive attention. ${ }^{25}$

Allow me to explain. In episodes of pretense, one can both pretend that $p$ and occurrently believe a proposition inconsistent with $p$. Pretense-Meredith can pretend I am loyal only to Carrie and occurrently believe I am loyal to the American government, and Pretense-John can pretend I am a bachelor and occurrently believe my wife and children are in the audience. In episodes of palief, however, one cannot palieve that $p$ and occurrently believe a proposition inconsistent with $p .^{26}$ If Meredith occurrently believes that she is loyal to the American government, she is not palieving. Why? Because palieving is, as it were, a sort of forgetting. I say "as it were" because one does not literally forget one's beliefs during episodes of imaginative transportation; the contents of one's Belief Box remain unchanged. But it is like forgetting in that one's attention turns away from one's actual beliefs and towards the beliefs, thoughts, and desires of one's

\footnotetext{
${ }^{24}$ In her cognitive model of imaginative immersion, Schellenberg [2013: 507-13] adds a Mixed Box to Nichols and Stich's [2003] boxology, where the Mixed Box contains both beliefs and imaginings. Liao and Doggett [2014] argue - persuasively, I think — that Schellenberg's addition to the boxology is insufficiently motivated. Regardless of the cogency of Liao and Doggett's specific criticisms, this much is clear: if my account explains imaginative transportation at least as well as that of Schellenberg (and I believe it does), then my account is preferable to Schellenberg's on account of parsimony.

${ }^{25}$ While Schellenberg [2013] and Liao and Doggett [2014: 270-1] note that attention has a role to play in immersion, Liao [unpublishable] is the first to propose an attentional account of immersion. Liao sums up his view with a slogan: "immersion is shift in attention" [unpublishable: 5]. While I accept Liao's account of immersion, imaginative transportation differs in that, unlike immersion simpliciter, transportation requires imaginings. At the same time, imaginative transportation is not simply imagination plus attention, as one reviewer proposed. I can imagine a liger and pay complete attention to the imagining, but I am not thereby engaging in imaginative transportation. Transportation, or virtually assuming another's noetic structure, is closer to what social psychologists mean by experience-taking than garden-variety imagination. ${ }^{26}$ Schellenberg [2013: 507] and Liao [unpublishable] are wise to this feature of imaginative transportation.
} 
character. ${ }^{27}$ It is consistent with pretense that one pretend that $p$ and consciously attend to the fact that not- $p$. It is inconsistent with palief that one palieve that $p$ and consciously attend to the fact that not- $p .^{28}$

We can frame the distinction in more explicitly boxological terms. In imaginative pretense, one attends simultaneously to the contents of one's Possible World Box and one's Belief and Desire Boxes. In imaginative transportation, one attends exclusively to the contents of one's Possible World Box. This is not to say that the mechanisms by which the details of pretense are filled out aren't roughly the same mechanisms by which the details of palief are filled out. In both palief and pretense, tokens are filtered from the Belief Box into the Possible World Box and used to generate pretense-based inferences. It is rather to say that in episodes of imaginative transportation, this process of filtering and inferring occurs outside of conscious awareness. Pretense-Meredith can consciously ask herself "what would Carrie's lackey do in this situation?" and make inferences on the basis of her answer. Palief-Meredith executes roughly the same cognitive operations, but she does it unconsciously. Indeed, Meredith doesn't need to ask herself "what would a lackey do?"; she just thinks like a lackey would think and does what a lackey would do, without any explicit metacognition.

This is how we should understand actors" talk of "getting lost in character" or "forgetting yourself." You do not actually forget truths about yourself, of course; your Belief Box retains its contents through episodes of transportation. Nor do you altogether lose the ability to access to your beliefs. If there is an on-stage gaffe, a good actor will consciously turn to her Belief Box (thereby interrupting the transportation episode) and exploit her beliefs about her fellow actors,

\footnotetext{
${ }^{27}$ Compare with Kaufman and Libby [2012: 2]: "In the process [of experience-taking], readers let go of key components of their own identity—such as their beliefs...-and instead assume the identity of a protagonist" (emphasis added). I suggest that we understand this "letting go" not in terms of relinquishing one's beliefs, but rather in terms of shifting one's conscious attention away from one's beliefs and desires.

${ }^{28}$ Compare with Liao [unpublishable: 6-7].
} 
her improvisational abilities, and so on, to ameliorate the problem. ${ }^{29}$ In this way, initiating a transportation episode is a matter of turning one's attention away from one's Belief and Desire Boxes and toward one's Possible World Box.

To this point, I have focused on cases like AGENT and GIOVANNI-what we might call cases of performative transportation. I have dedicated less space to cases like READER-what we might call cases of aesthetic transportation. While I think the model developed here can accommodate aesthetic transportation, some clarifications are in order. Like performative transportation, aesthetic transportation requires virtually assuming the thoughts and feelings (though not necessarily the behaviors) of a character. And like performative transportation, aesthetic transportation is efficacious and requires commitment. ${ }^{30}$ One might retort, however, that aesthetic transportation is less demanding and skillful than performative transportation or even garden-variety reading. In general, one doesn't try to lose oneself in a novel, play, or film; it just happens. Moreover, it is often harder to maintain psychic distance from a work of art— to actively fight the impulse to enter another world - than it is to engage in aesthetic transportation. But isn't this inconsistent with the account on offer? ?1 $^{31}$

I acknowledge that aesthetic transportation is at least sometimes less demanding and skillful than both performative transportation and garden-variety aesthetic experience. ${ }^{32}$

${ }^{29}$ It is compatible with my account that one can temporarily lose the ability to redirect attention to one's Belief and Desire Boxes during episodes of pretense. This phenomenon enjoys some anecdotal support. For example, actor Jim Carrey reportedly had trouble "snapping out of character" on the set of the Andy Kaufman biopic Man on the Moon [Liao and Doggett 2014: 259].

30 As Robert Duffy noted, it is not obvious in what sense character assumption is more effective than pretense. I don't have a knockdown response, but some provisional suggestions might help. Again consider READER. Perhaps Sandra, by virtue of identifying herself with Frankenstein, experiences profounder aesthetic emotions than Pretense-Sandra. Or perhaps Sandra is in a better position to apprehend certain truths about the human condition than Pretense-Sandra. If reading fiction is a way of expanding one's perspective on the world, gaining insight into the human condition, and fostering sympathetic dispositions, then Sandra appears to have a leg up on Pretense-Sandra. See Schellenberg [2013: 507-8], Green and Donahue [2009: 243, 247-9], and Kaufman and Libby [2012] on the moral and epistemic benefits of character assumption, as well as Walton [1990: 271-4] on the purpose of immersion in fiction.

${ }^{31}$ I am thankful to Jason D'Cruz and Robert Duffy for pressing an objection along these lines.

32 There is a sense, however, in which aesthetic transportation is more demanding than mere aesthetic experience: aesthetic transportation is singularly exhausting. Enraptured readers, viewers, and listeners are 
Fortunately, this can be explained on the present model. In episodes of aesthetic transportation, the contents of one's Possible World Box are supplied not just by one's Belief Box, but also by the author, playwright, or director. When reading The Lord of the Rings, you needn't ask yourself "what is Frodo thinking?" at every turn. Much of the time, Tolkien just tells you what Frodo is thinking. Because a significant amount of the imaginative work is offloaded onto the author, it is comparatively easy for a reader to engage in aesthetic transportation.

In performative transportation, however, actors assume much more of the cognitive burden. While some details are filled by the artist—indeed, this is part of the task of playwrights and directors - actors generally have less guidance and more interpretive latitude than audience members. Moreover, it is easier to keep your attention fixed exclusively on your Possible World Box when the contents are being filled in by someone else. It is harder to maintain focus when you are filling in the contents-when you are forced to create and enact act the same time, all outside of conscious attention. ${ }^{33}$

The forgoing analysis helps us explain other closely related, readily observable phenomena. First, it is generally easier to lose oneself in fluid or descriptive prose than in difficult or sparse prose. Aesthetic transportation comes more readily when reading The Lord of the Rings than Ulysses. Indeed, this is to be expected. The more information the author provides and the easier it is to assimilate the information provided, the less one relies on one's Belief Box to fill in the details and the easier it is to engage in aesthetic transportation. Second, it is easier to immerse oneself in a role when one has done preparatory research. ${ }^{34}$ This too is to be expected. The less "on the fly" imaginative work you have to do, the less cognitive load you assume, and the easier it is for you to fix your attention exclusively on your Possible World Box. And third,

prone to clenching their fists, gasping, and even weeping. Losing oneself in another person's inner life is draining in a way that mere imagining is not.

33 I am grateful to Jason D’Cruz for a similar suggestion. See Liao [unpublishable: 5-7] for a transportation-friendly account of conscious attention.

${ }^{34} \mathrm{I}$ am again indebted to Jason D'Cruz. 
aesthetic transportation requires far less training than performative transportation. ${ }^{35}$ It is comparatively easy to fix your attention on your Possible World Box when the contents are being filled in by someone else. It is considerably harder to imaginatively produce new beliefs, funnel them from the Belief Box to the Possible World Box, and maintain complete focus on one's Possible World Box. The former requires no training; the latter is grueling even with training. ${ }^{36}$

We are finally in a position to put the pieces together. To engage in imaginative transportation with respect to $p$ is to palieve that $p$. To palieve that $p$ is to virtually assume a noetic structure that includes $p$. To virtually assume a noetic structure that includes $p$ is to cognitively attend only to the contents of one's Possible World Box, where one's Possible World Box contains a representation token with content $p$.

\section{Concluding Remarks}

I opened this paper with a poem by Emily Dickinson. While the transportation metaphors might come off trite to contemporary readers, this is only because the metaphors are so obviously fitting. ${ }^{37}$ Indeed, in both imaginative transportation and garden-variety transportation, we experience displacement. The difference is just the nature of the displacement: the latter is physical, the former attentional. We can drive the point home by coopting Dickinson's imagery, albeit with a philistine stiltedness that only a philosopher could stomach. In episodes of imaginative transportation, the Frigate of conscious attention takes us away from Belief/Desire Land and docks at Possible World Land. As representation tokens are shipped from

${ }^{35}$ I am thankful to Robert Duffy for the insight. An anonymous reviewer added that children routinely engage in aesthetic transportation when they are read to, despite being unskilled in the art of transportation. I'm in agreement.

${ }^{36}$ See Green and Donahue [2009: 245-6] and Liao, Strohminger, and Sripada [2014] for further discussion of transportability (i.e., ease of aesthetic transportation) and its modulating factors. See Walton [1990: 27489] for an analysis of art appreciation without immersion, along with discussion of artworks designed to frustrate transportation. Finally, see Liao and Gendler [2016] for a survey of philosophical literature on imaginative resistance.

${ }^{37}$ See Green and Donahue's [2009: 241-2] treatment of transportation metaphors in Dickenson's poem. 
Belief/Desire Land to Possible World Land, the Frigate remains stationed at Possible World Land. Sometimes, the waters are still (as in much aesthetic transportation); other times, the waters are troubled (as in much performative transportation). In the former case, novices remain docked without breaking much of a sweat. But in the latter case, an expert is needed to fight the waves that constantly threaten to push the Frigate back to Belief/Desire Land.

So contrary, perhaps, to the last few lines of Dickinson's poem, imaginative transportation is costly. It cannot be bought, of course, but it is taxing. Aesthetic transportation occupies one's cognitive resources and often leaves one feeling emotionally drained. Performative transportation requires considerable skill and brings with it no guarantee of success. In a word, imaginative transportation is consuming. But this is as it should be. We can think of imaginative transportation as a sort of cross-cultural immersion-taxing and consuming, yes, but immensely rewarding.

In a well-worn primer on participant observation-the ethnographic practice of gaining insight into a foreign culture by participating in its customs-James Spradley [1980] reflects on the epistemic value of cultural immersion. I shall give him the final word, inviting the reader to consider his reflections through the lens of imaginative transportation:

Immersion is the time-honored strategy used by most ethnographers. By cutting oneself off from other interests and concerns, by listening to informants hours on end, by participating in the cultural scene, and by allowing one's mental life to be taken over by the new culture, themes [the implicit beliefs of a culture] often emerge...This type of immersion will often reveal new relationships among domains and bring to light cultural themes you cannot discover any other way [1980: 145]..$^{38}$

\section{Fordham University}

${ }^{38}$ I am grateful to Scott Aikin, Robert Farley, and participants of the Philosophers' Cocoon Philosophy Conference (October 2016) and the New York Pragmatist Forum (January 2017) for helpful comments on several ancestors of this paper. I am especially grateful to Nathan Ballantyne, Jason D'Cruz, Robert Duffy, Carolyn Garland, Diana Heney, Shen-yi Liao, Ray VanArragon, and two anonymous reviewers, whose detailed and thoughtful comments on the present version of this paper (and several earlier versions in the case of Ballantyne and Heney) significantly improved the final product. I also received many excellent comments from participants of the Red Star Line Conference at the University of Antwerp (August 2017) and the 163' Meeting of the Creighton Club at Syracuse University (September 2017). 


\section{References}

Andreou, A. 2014. Being an Actor? I'll Bet You Think I Could Do That, The Guardian, URL = $<$ https://www.theguardian.com/commentisfree/2014/apr/17/being-an-actor-difficultjob>.

Brody, R. 2014. Is Method Acting Destroying Actors? The New Yorker, URL = $<$ http://www.newyorker.com/culture/richard-brody/is-method-acting-destroyingactors $>$.

Chasid, A. 2017. Imaginative Content, Design-Assumptions and Immersion, Review of Philosophy and Psychology 8/2: 259-72.

Cohen, L.J. 1992. An Essay on Belief and Acceptance, Oxford: Oxford University Press.

Gendler, T.S. 2008. Alief and Belief, The Journal of Philosopby 105/10: 634-63.

Green, M.C., and J.K. Donahue. 2009. Simulated Worlds: Transportation Into Narrative, in Handbook of Imagination and Mental Stimulation, ed. K.D. Markman, W.M.P. Klein, and J.A. Suhr, New York: Psychology Press: 241-54.

Kaufman, G.F., and L.K. Libby. 2012. Changing Beliefs and Behavior through ExperienceTaking, Journal of Personality and Social Psychology 103/1: 1-19.

Langland-Hassan, P. 2014. What it is to Pretend, Pacific Philosophical Quarterly 95/1: 397-420.

Liao, S. unpublishable. Immersion is Attention / Becoming Immersed, URL = $<$ https://philpapers.org/rec/LIAIIA $>$.

Liao, S., and T. Doggett. 2014. The Imagination Box, The Journal of Philosophy 111/5: 259-75.

Liao, S., and T.S. Gendler. 2011. Pretense and Imagination, Wiley Interdisciplinary Reviews 2/1: 7994.

Liao, S., and T.S. Gendler. 2016. The Problem of Imaginative Resistance, in The Routledge Companion to the Pbilosophy of Literature, ed. N. Carroll and J. Gibson, New York: Routledge: 405-18.

Liao, S., N. Strohminger, and C.S. Sripada. 2014. Empirically Investigating Imaginative Resistance, British Journal of Aesthetics 54/3: 339-55.

Nichols, S., and S. Stich. 2000. A Cognitive Theory of Pretense, Cognition 74/2: 115-47.

Nichols, S., and S. Stich. 2003. An Integrated Account of Pretence, Self-Awareness, and Understanding Other Minds, New York: Oxford.

Ohikuare, J. 2014. How Actors Create Emotions: A Problematic Psychology, The Atlantic, URL $=<$ https://www.theatlantic.com/health/archive/2014/03/how-actors-create-emotionsa-problematic-psychology/284291/>.

Plantinga, A. 1983. Reason and Belief in God, in Faith and Rationality, ed. A. Plantinga and N. Wolterstorff, Notre Dame, IN: University of Notre Dame Press: 16-93.

Price, H.H. 1969. Half-Belief, in Belief, New York: Humanities Press: 302-14.

Schellenberg, S. 2013. Belief and Desire in Imagination and Immersion, The Journal of Philosophy 110/9: 497-517.

Schwitzgebel, E. 2001. In-between Believing, The Philosophical Quarterly 51/202: 76-82.

Spradley, J.P. 1980. Participant Observation, New York: Holt, Rinehart and Winston.

Walton, K.L. 1990. Mimesis as Make-believe: On the Foundations of the Representational Arts, Cambridge, MA: Harvard University Press.

Wu, W. 2011. What is Conscious Attention? Philosophy and Phenomenological Research 82/1: 93-120. 